Meta

Journal des traducteurs

Translators' Journal

\title{
Les fantômes en télévision
}

\section{Jean Baudot}

Volume 26, numéro 4, décembre 1981

URI : https://id.erudit.org/iderudit/002007ar

DOI : https://doi.org/10.7202/002007ar

Aller au sommaire du numéro

Éditeur(s)

Les Presses de l'Université de Montréal

ISSN

0026-0452 (imprimé)

1492-1421 (numérique)

Découvrir la revue

Citer cet article

Baudot, J. (1981). Les fantômes en télévision. Meta, 26(4), 376-377.

https://doi.org/10.7202/002007ar

Ce document est protégé par la loi sur le droit d'auteur. L’utilisation des services d'Érudit (y compris la reproduction) est assujettie à sa politique d'utilisation que vous pouvez consulter en ligne.

https://apropos.erudit.org/fr/usagers/politique-dutilisation/
Cet article est diffusé et préservé par Érudit.

Érudit est un consortium interuniversitaire sans but lucratif composé de l'Université de Montréal, l'Université Laval et l'Université du Québec à Montréal. Il a pour mission la promotion et la valorisation de la recherche. https://www.erudit.org/fr/ 


\section{LES FAN'TÔMES EN TÉLÉVISION}

Tous les téléspectateurs connaissent les désagréments que provoquent les images fantômes (ghost images) sur leur petit écran. Dans certains endroits, ou lors du passage d'un avion, une deuxième image parasite apparaît sur l'écran et la qualité de réception en est sérieusement affectée. Les télédiffuseurs connaissent bien ce problème et une réglementation gouvernementale exige que de minutieux calculs soient effectués avant l'installation de toute nouvelle antenne de transmission pour minimiser la production d'images fantômes dans la région couverte par la nouvelle antenne. Dans la terminologie technique anglaise, décrivant ou réglementant ce phénomène, on trouve une foule de ghost words pour lesquels les dictionnaires techniques ne semblent pas proposer d'équivalents français.

Il s'agit, en fait, d'un problème d'écho. Les ondes électromagnétiques sont réfléchies par les structures métalliques (ghost structure) ou autres antennes (ghost tower) environnantes et un deuxième signal, un écho (ghost signal), se propage avec un certain retard (ghost delay) par rapport à celui de l'antenne émettrice provoquant ainsi des images fantômes sur l'écran du téléspectateur. L'éventuel télédiffuseur, lorsqu'il choisit un site pour une nouvelle antenne de diffusion, doit mesurer les effets d'échos qui se manifesteront dans la région qu'il veut desservir.

Si «image fantôme» est accepté, on peut difficilement, en français, apposer fantôme à tous les termes qui décrivent ce phénomène sans créer des néologismes cocasses (comme «calcul fantôme», «structure fantôme», «mesure fantôme», etc.). Comme il s'agit avant tout d'une question d'échos ou de réflexions parasites, ce sont plutôt ces termes qui nous semblent appropriés dans une terminologie française.

Voici quelques termes que nous avons relevés dans une publication gouvernementale et pour lesquels nous proposons des équivalents : 


ghost prediction
ghosting interference
ghosting problem
ghost structure
ghost tower
ghost delay
ghost level
ghost magnitude
ghost signal
ghost/signal ratio
ghost computation
ghost equation
ghost measurement
ghost situation
ghost impairment

prédiction des (effets dus aux) échos interférence due aux échos [réflexions] problème d'écho [de réflexion] structure écho [de réflexion] pylône (d'antenne) écho [de réflexion] retard d'écho niveau d'écho amplitude d'écho signal écho [réfléchi] rapport écho/signal calcul des (effets dus aux) échos équation d'écho mesure d'écho situation d'écho détérioration (de l'image) due aux échos

La traduction de la plupart des termes pourrait se faire en utilisant les mots «écho» ou «réflexion» pour spécifier adéquatement le phénomène. Par exemple, dans certains milieux, on utilise «antenne anti-réflexion» pour rendre ghost tower. Toutefois, nous préconisons plutôt l'emploi du mot «écho» qui semble mieux véhiculer le caractère parasite du phénomène, au même titre que le fait ghost. Nous soumettons ces termes à la réflexion des lecteurs en les remerciant d'avance pour leurs commentaires et précisions.

JEAN BAUDOT

\section{BIBLIOGRAPHIE}

Commission Électrotechnique Internationale (1979): Vocabulaire électrotechnique international, Genève, Bureau central de la C.E.I.

Direction générale de la terminologie et de la documentation (1978) : Bulletin de terminologie 151 - Électrotechnique, Hull, Approvisionnements et services Canada.

NEIDHARDT, P. (1964): Dictionary of Television Engineering and Electronics, Berlin, Pergamon Press.

CLASON, W.E. (1955): Dictionary of Television, Radar and Antennas, Amsterdam, Elsevier.

DAVID, P. et VOGE, J. (1966) : Cours de radioélectricité générale, tome IV, propagation des ondes, Paris, Eyrolles.

LEVITAN, Eli L. (1970): An Alphabetical Guide to Motion Picture, Television and Videotape Production, New York, McGraw-Hill.

PANNETT, W.E. (1967): Dictionary of radio and television, Ncw York, Philosophical library.

MONTI, A. (1975) : Mémento d'électronique et de radiotechnique. Propagation et antennes, Lausanne, EPSIC.

COLLIN, Robert E. and ZUCKER, Francis J. (1969): Antenna Theory, vol. 1 et 2, New York, McGraw-Hill. 